\title{
Dynamic Characteristics of Micro-Cracked Park Gear under Transient Shock Input
}

\author{
Chan-Jung Kim', Ho-Young Kang ${ }^{2}$, Young-Geun Song ${ }^{2}$, Eric Lee ${ }^{3}$, Patrick Seo ${ }^{3}$ \\ ${ }^{1}$ Department of Mechanical Engineering, Pukyong National University \\ 365, Sinseon-ro, Nam-gu, Busan, South Korea \\ cjkim@pknu.ac.kr \\ ${ }^{2}$ Institute of Green Car Parts, Future Car Research Center \\ 120, Gongdan 7-ro, Jinyang-eup, gyeongsan-si, South Korea \\ hykang@gbtp.or.kr; younggeun@gbtp.or.kr \\ ${ }^{3}$ Hanho Industry Company, Overseas Marketing Department \\ 167, yeongcheonsandan-ro, geumho-eup, Yeongcheon-si, South Korea \\ eric.lee@hanhoinc.com; patrick.seo@hanhoinc.com
}

\section{Extended Abstract}

A park gear module of a ground vehicle system is one of important component to activate parking mode with a mechanical interruption on a gearbox module and forging machines has been used to manufacture park gears under high pressured-plastic deformation. During the manufacturing process, some micro cracks are evitable on the surface of park gears so that the crack checking of the park gear is mandatory step during quality control inspection. The criterion of crack checking is based on 50 micro meter $(50 \mu \mathrm{m})$ and every manufactured park gear module should not exceed the maximum crack size $50 \mu \mathrm{m}$. The crack length criterion is associated with the static characteristics of a gear part that make sure the reliable static resistance performance over severe torque conditions. However, a vehicle system may be controlled under many complicated driving modes by the willingness of human drivers as well as exposed to hundreds of different road surfaces and a park gear part is impossible to be isolated from those dynamic loadings, either. So, the park gear module is technically required additional reliability checking process related dynamic behaviour that has not been considered so far. There are many types of dynamic loads [1] that can affect the target park gear during operation and the transient shock load is very critical condition that may accelerates the micro-cracked park gear module because the crack propagation in a mechanical system is very susceptible for transient shock condition [2].

In this paper, the dynamic characteristics of micro-cracked park gear is experimentally analysed with a highly accelerated life test (HALT) whether the influence of the transient shock stress is sensitive for the micro-cracked park gear. The shock level was controlled at $40 \mathrm{~g}$ (r.m.s.) under room temperature and the length of crack was previously measured by 3D X-ray scanner. The dynamics of selected park gear module was also identified with impact testing [3] so that the frequency response function between the gear body and the crack location was obtained. After HALT test, same inspection processes, that is 3D X-ray scanning and impact testing, were followed at the same condition and test results (before and after HALT) were collected to compare them.

The existing micro-crack at the surface of gear park module was somewhat propagated under the transient shock input but the variation of crack length was not clear to evaluate it from the scanned figures directly. But the discrepancy between two frequency response function shows considerable at resonance frequency so that single resonance peak is bifurcated into two peaks. Therefore, it could be concluded that the transient shock stress is very sensitive to the micro-cracked park gear so that additional quality control inspection, such as HALT, is recommended to be considered at the manufacturing of a park gear module.

\section{References}

[1] C. Lalanne, Fatigue damage. Hoboken, NJ: John Willey \& Sons, Inc., 2014.

[2] Y. L. Lee, M. E. Barkey, H. T. Kang, Metal fatigue analysis handbook, Waltham, MA: Elsevier, 2012. 
[3] D. J. Ewins, Modal testing. Baldock, Hertfordshire: Research Studies Press Ltd., 2000. 